\title{
First-time fathers' experiences of normal childbirth
}

\author{
Anna Ledenfors and Carina Berterö
}

Journal Article

\section{Tweet}

N.B.: When citing this work, cite the original article.

Original Publication:

Anna Ledenfors and Carina Berterö, First-time fathers' experiences of normal childbirth, Midwifery, 2016. 40(), pp.26-31.

http://dx.doi.org/10.1016/j.midw.2016.05.013

Copyright: Elsevier

http://www.elsevier.com/

Postprint available at: Linköping University Electronic Press

http://urn.kb.se/resolve?urn=urn:nbn:se:liu:diva-131269

(@) $\odot \Theta \Theta$ 
Title: First-time fathers' experiences of normal childbirth

Anna Ledenfors, RNM, MScN, ${ }^{a}$ Carina Berterö, RNT, PhD, Professor ${ }^{\mathrm{b}}$

${ }^{a}$ Midwife Clinic, Department of Obstetrics and Gynaecology

Vrinnevi Hospital

SE-603 79 Norrköping, Sweden

${ }^{b}$ Division of Nursing Science, Department of Medicine and Health Sciences

Faculty of Medicine and Health Sciences, Linköping University

SE-581 83 Linköping, Sweden

Correspondence: Carina Berterö

Division of Nursing Science, Department of Medicine and Health Sciences

Faculty of Medicine and Health Sciences, Linköping University

SE-581 83 Linköping, Sweden

Phone: + 4613286974,0732702270

E-mail: carina.bertero@liu.se 


\section{Highlights}

- Prospective fathers experience a wide range of emotions during childbirth

- Prospective fathers wish to be recognized as part of a unit with the mother-to-be

- Needs of prospective fathers to be given more recognition during childbirth

- The midwife is important for prospective fathers both before and during childbirth

- Information and support from the midwife positively affect the experience of childbirth 


\section{Abstract}

Objective: To identify and describe first-time fathers' experiences of normal childbirth.

Design: A qualitative interview study using a thematic analysis for analysing the transcripts. Participants: Purposeful sampling was used. Eight men were interviewed two to six months after experiencing childbirth. Participants were men who had become fathers for the first time. Setting: A county located in the middle of Sweden covering both urban and rural areas.

Findings: The analysis resulted in one major theme - a transformative experience - with four sub-themes: preparing for childbirth, feeling vulnerable in a new situation, being confirmed as part of a unit, and meeting their child for the first time.

Key conclusions: The findings indicate that the needs of prospective fathers should be given more recognition during childbirth. The findings also show that the midwife is an important person for prospective fathers, both before and during the birth.

Implications for practice: The findings of the study show what affects first-time fathers' experiences of childbirth. By listening to fathers and recognizing them as part of a unit with the woman giving birth, midwifes can support them and increase their participation. Thereby, they can find their role in an unfamiliar situation and thus have a positive experience of childbirth.

Key words: first-time father, experiences, childbirth, qualitative study, thematic analysis 


\section{Introduction}

Having a baby is one of life's major events. The attendance of prospective fathers during childbirth is taken for granted and they are expected to support the woman giving birth, which means being at her side (Premberg et al., 2011). Studies have shown that fathers experience labour as a positive but demanding event and they express that information for prospective fathers is lacking. There is also a need for support for the fathers themselves (Bäckström and Hertfelt Wahn, 2011; Johansson et al., 2012; Johansson et al., 2015; Lindberg and Engström, 2013; Premberg et al., 2011).

Before 1960 the prospective father was seen as an inconvenience in the delivery room as he could faint or somehow hinder the care of the woman. He was also seen as a person that could spread infections (Bedford Johnson, 1988; Peterson, et al., 1979). Later it became evident that the prospective father had a desire to share the birthing experience with his partner. New preparation courses were implemented and they focused on both expectant parents. The prospective father was now in the position of coaching the woman during the birth (Hagström, 1999). Prospective fathers have been encouraged to attend births since the 1970s. A once womanly domain has elevated the importance of the role of the expectant father. The attitude about the importance of the prospective father's attendance during childbirth gradually came to include his relation with the infant (Hagström, 1999).

In a study by Chandler and Field (1997), the prospective father described how he is seen as just an accompanying partner to the woman in labour and not as a part of a couple delivering a child. The prospective fathers' own point of view is that they are a part of a couple going through childbirth. This is also expressed in another study by Steen et al. (2012) where the prospective father viewed himself as a partner and parent during the pregnancy and birth, but felt he was not seen or recognised in the healthcare system as such. If the prospective father does not experience support, does not feel included and is not well prepared for pregnancy, birth and parenthood, he will not be able to support his partner in an appropriate way to best reach a transition to positive parenthood (Steen et al., 2012). It is important that the prospective father can prepare himself and practice a coaching role (Chandler and Field, 1997; Dellmann, 2004). Preparation for childbirth is an important factor if it is to be a positive experience (Bergström et al., 2013). 
Li Poh et al. (2014) pointed out that during the pregnancy and birth the prospective father experiences several different emotions: euphoria, happiness, shock and anxiety. The authors also describe how the prospective father adapts his behaviour to support his partner. This is confirmed by Johansson et al. (2015) and Vehviläinen-Julkunen et al. (1998) who describe the prospective father wanting to actively participate during childbirth and to be respected for his input. However, the prospective father often experiences overwhelming emotions and feelings of being incapable of supporting his partner during the birth. The prospective father suffers when he sees his partner in pain, which can be relieved if he takes an active part in the birth by giving reassurance and security by assisting and caring for the mother. He needs support from healthcare professionals in this mission. The woman giving birth is seen as the obvious focus of attention, and in order to be able to support and strengthen her, his own needs and emotions (i.e. helplessness, doubts and pain) are put aside. This highlights a need to confirm the father's supporting role and also to recognize him as a vulnerable person (Johansson et al., 2012; Lundgren and Berg, 2007).

The prospective father's attendance in the delivery room is important. It is important for the woman giving birth to have support; this contributes to her well-being but it is also important in terms of the father's attachment to the child (Vehviläinen-Julkunen and Liukkonen, 1998). His presence during childbirth may also have a positive influence on the intellectual development of the child (Amato, 1994; Hildingsson et al., 2011; Premberg et al., 2011; Trautmann-Villalba et al., 2006).

There are few studies focusing on first-time fathers' experiences (Premberg et al., 2011; Chandler and Field, 1997), but there are some studies about fathers' experiences and participation in childbirth which also point out the importance of the midwife (Johansson et al., 2012; Longworth et al., 2015; Longworth and Kingdon, 2011; Vehviläinen-Julkunen and Liukkonen, 1998). As a result, it is important to study first-time fathers and gain more knowledge and understanding of these men's experiences that could give the midwife the means to supply optimal care for both the prospective mother and father. The aim of this study therefore was to identify and describe first-time fathers' experiences of normal childbirth. 


\section{Method}

A qualitative approach appropriate for an open exploration including description and understanding of the first-time fathers' experiences was utilized (Kvale and Brinkmann, 2014). Semi-structured interviews explored their experiences and data were analysed with thematic analysis (Braun and Clarke, 2006).

\section{Sample}

Inclusion criteria were first-time fathers who understand and speak Swedish. The childbirth should have been normal (not an assisted delivery; forceps and ventouse or caesarean) and a maximum of six months before. The exclusion criterion was a delivery where mother or child was not doing well, i.e. there were complications affecting their health. Female partners were excluded from this study since the aim was to focus on first-time fathers' experiences.

Participants were recruited via posters displayed on maternity wards, six different child welfare centres and three open day nurseries in a county in South East Sweden. The same poster was also published on the authors' Facebook site, encouraging friends to share it further. This resulted in 105 shares. This poster only gave a little information and included a link to the authors' homepage where they could read more about the study. The prospective participants communicated their interest via e-mail. Twelve first-time fathers reported an interest, out of which four were excluded: two births had been complicated; one birth had taken place more than six months previously; and one first-time father was excluded due to confusion regarding languages (not fluent in Swedish or English). None of the participants were known to the authors.

Eight first-time fathers were included in the study and informed consent was obtained before the interview. The fathers were aged between 23 and 45 and they had become fathers two to six months before. All pregnancies were wanted. Out of these eight first-time fathers, six had participated in parent education. Three of the fathers had an upper secondary school education, five had a university education and all were full time employed. The fathers came from both rural and urban settings but all the first-time fathers went through the childbirth process at the same hospital. 


\section{Data collection}

The interviews were scheduled to take place in a location chosen by the fathers and were conducted between September 2014 and January 2015.

All interviews were conducted using an interview guide containing three areas of interest: the father's own experience of the birth, his role during the labour, and his relationship with the midwife. Every interview started with the open-ended question 'Can you tell me about your experience of the birth?' in order to make the fathers speak openly and honestly. To get a deeper understanding and to clarify some parts of the interview, questions such as 'Can you tell me more about that?’ or 'Can you clarify that?' were asked (Kvale and Brinkmann, 2014). The interviews were digitally voice-recorded and lasted for 10-60 minutes (median was 23 minutes).

\section{Data analysis}

The eight verbatim transcripts were analysed using thematic analysis (Braun and Clarke, 2006). In fact, thematic analysis is a useful and flexible method for qualitative research that searches for themes or patterns (Braun and Clarke, 2006). The analysis was a continuous reading of the text while following the principles of thematic analysis. During this process, initial ideas were noted in order to become familiar with the data, and the statements were then coded. The codes were reviewed and put into potential themes. After that, themes and subthemes were identified, data were compared, and a thematic map was created to give a better overview. Finally, an ongoing analysis was conducted to refine the characteristics of each theme and to find the story of the analysis - presenting the meaning of the theme (Braun and Clarke, 2006).

Braun and Clarke (2006) devised a 15-point checklist of criteria for good thematic analysis. We tried to follow all these criteria to ensure that a good and reliable thematic analysis was provided. The data were transcribed to an appropriate level of detail, each piece of data was given equal attention in the coding process, themes were checked against each other and back to the original data set. Data were analysed and interpreted, not just described, ensuring meaning was given to data. As mentioned above we were two persons doing the analysis, to balance out the subjective influences of individuals (Flick,von Kardoff \& Steinke, 2004).

In order to ensure trustworthiness/validity of data and data presentation; the data collection and analysis is clear presented and follow the method. The findings are written in such a way 
that it can be experienced and understood by the readers as directed to them (Flick,von Kardoff \& Steinke, 2004).

\section{Ethical considerations}

The study was performed in accordance with the Declaration of Helsinki and Swedish legislation of non-invasive studies (WMA, 2013; SFS 2003:460, 2008:192). According to Swedish law, ethical approval is not required for research studies conducted during advanced educational programmes, but all considerations in the study were made in accordance with ethical laws and guidelines.

Participants were informed that they could leave the study at any time and the interview material would remain confidential at all times.

\section{Findings}

A main theme was identified during the analysis: transformative experience. Four subthemes were also identified: preparing for childbirth, feeling vulnerable in a new situation, being confirmed as part of a unit, and meeting their child for the first time. These are illustrated in Figure 1.

The findings are described below and illustrated with quotations from the first-time fathers. Quotations are presented with numbers from the interview they are taken from.

Please insert Figure about here

\section{A transformative experience}

The father-to-be undergoes a totally new experience: childbirth in an unfamiliar environment at the delivery unit. This encounter also includes new people, with whom the expectant father needs to interact and cooperate. Childbirth can also be an unpredictable process and this can cause the father to feel insecure. There are often both expectations and apprehensions about how the labour and birth will proceed. Being at the side of the woman giving birth means being present in a situation that can be demanding and transformative, but with help from the midwife it can be safe and joyful. The father-to-be strives to be a support for his partner and needs confirmation in his role as the supportive person. The birth of a first child entails an awareness that life will now change; this is a great moment for the father, which involves 
many different emotions for him. Many are emotions of joy and happiness but there are also emotions of shock and insecurity regarding the new life.

"It is a well-defined moment in life. Hmm... you are aware that everything will change... afterwards you have... you realize that you view your life as before and after getting a baby. Hmm...about how to define your life, how to evaluate your life.” (3)

\section{Preparing for childbirth}

Most fathers-to-be have prepared practically with the expectant mothers for the birth. Bags are packed, the route to the hospital is clear, and the home is prepared for the child's arrival. But it is harder to prepare mentally: what will it be like at the delivery unit when it actually happens? There are many apprehensions about a hectic environment with a lot of activity at the unit. This preparation includes thoughts about what it will be like meeting their first baby. It is one thing to be ready in a practical sense for this first child, but it is something else to fully understand what this new life means.

"You thought that you were prepared, but you were not...not before you had...had the child in your arms...then you realized that you were not as prepared as you thought..." (1)

The expectant fathers had an internal picture and perception about what the birth would be like: taking part in parent education courses, looking at films about childbirth and talking to other people around them had given them some information. This information made them worry that the woman's first labour could be protracted and also that she would be in extreme pain. Some of the fathers-to-be had not looked at any information about childbirth beforehand. One of them reflected if that was perhaps a conscious decision because he had not been forced to do so. Some of the fathers chose to take the birth as it came; those fathers expressed the expectation that everything would go well.

When labour starts some days before the estimated due date and the expectant mother has not had any contractions prior to this, the expectant father feels unprepared and surprised by the start of the contractions. It is the other way around if the woman goes beyond her estimated due date as the fathers can mentally prepare themselves and they are aware that the contractions can start at any time. They are constantly in a state of preparedness for the birth. Regardless of whether the birth is quicker or more protracted then expected, most of the fathers state that the picture they previously had about childbirth does not reflect the reality of the event. 
"... as for me, it was interesting to see...you have just seen movies...what is happening...it was not like that at all!” (7)

Several of the fathers state that the childbirth went much better than expected. They also express that giving birth was a greater and better experience than they had anticipated. When the birth actually goes faster than expected, the fathers see it as a positive experience and describe it as a relief.

"It went so quickly...quickly and smoothly and well for us...no problems, no complications, nothing...everything just went on in one sweep...nothing that spoiled it ...it was really nice...much quicker and easier than I thought it would be...expectations were different actually... I thought it would be much worse... in all ways... so it was a relief...” (8)

\section{Feeling vulnerable in a new situation}

In this new and unfamiliar situation - childbirth - the expectant fathers experience several different emotions and they have no frame of reference. Managing the unfamiliar means feeling insecure, which creates an inner stress within these men. When the expectant parents arrive at the delivery unit, the labour is in an intensive phase and several of the fathers express that their focus is to get into the building as fast as possible. There is also insecurity about the process of childbirth: how long can the active phase of bearing down go on? Not having sufficient information or knowledge about childbirth could also produce a feeling of being an outsider. Even so, the expectant fathers try to follow the process in different ways and they feel inadequate in their role as the supporting person at the side of the woman giving birth. When the expectant father himself experiences doubt about how to support his partner, it adds to the insecurity of the whole childbirth process. Not knowing what to do contributes to this feeling of insecurity.

"...was there something more I should have done?...but I did not know ... it was just not like me to sit there beside her...and doing nothing... "(7)

During the birth the expectant fathers occasionally experience fear. They do not always follow and understand the process of a normal childbirth or when something happens and extra healthcare professionals come in. Some of the fathers compared this fear to being paralyzed and they just needed to try to keep themselves together. This fear is also related to worries about something being wrong with the child, especially when action is taken to 
monitor the baby during childbirth - for example, applying electrodes to the child's head.

Giving the expectant fathers clear information about what is happening and why would reduce fear and vulnerability, according to the fathers' statements. Some of the fathers also experience fear about how the woman will manage the pain of childbirth. One of the fathers described himself as being inside a bubble as his partner gave birth. He states that being in this bubble helped him through this painful moment and he managed to control his fear. When someone spoke to him, his awareness increased and he became part of a difficult situation. It was hard to be outside the bubble; it felt calmer and more secure to stay at a distance.

"One of the nurses started to talk to me. Then it was much tougher. Otherwise, you can just stand there and watch and not think so much. You went inside yourself in some way. Luckily, she did not say so much. It wasn't really difficult, but it created a different feeling.......when she asked me 'How are you doing?' So that was... it was almost harder. Then I started to think about myself instead of just thinking about her [the woman giving birth]...” (2)

The fathers describe feeling captured in the intense birthing process where nothing else exists; they are present in the here and now. There is no other way out other than the woman giving birth to the child. The expectant fathers feel powerless about what is expected from them. They describe a very difficult experience; they can do nothing to mitigate this and this leads to feeling inadequate.

When the end of the labour approaches and the baby is about to be born, the fear is accelerated within the majority of the fathers. The realisation that the birth is imminent is very powerful. Thinking of childbirth as a natural part of life and that the pain the woman experiences is not dangerous and only lasts a relatively short time gives the expectant fathers some comfort in a situation where they are powerless and vulnerable.

\section{Being confirmed as part of a unit}

Fathers-to-be are prepared to be supportive during childbirth since they realise that this will not be an easy task for the woman. They express that before the birth they did not realise how important their role was for the woman. In their endeavour to be a support for the woman in labour, the expectant fathers try to be a part of the process in different ways: by being present, helping her to relax between the contractions, breathing with her, and being a physical and mental support during the whole process. 
The fathers-to-be focus exclusively on the woman and state that their own needs are put aside. They see childbirth as a shared experience where both persons are important. The expectant fathers describe feeling that they want to compensate for the fact they are not able to take away the pain from the woman. Instead, they try to contribute with confidence to help her endure the process.

"All the focus is on her...try to make it as good I can...be a great support...and just being two centimetres away, standing there...feeling the hand or you could feel the...voice...well...it...it is a feeling of confidence and that is big for me...I try to stand there stable by her side...and calm... which she is not able to be in that moment. That is my task - trying to be that... that part in... as a partner. Since this is...this is our, this is our experience, it is our... that is coming... out of this...” (4)

Most of the expectant fathers stated that it was important to have something meaningful to do during childbirth. In that way, they feel they have a valuable role and that they are doing something good. Some of the fathers reflected upon their role during childbirth and described it as small and passive. They are just present and wonder if there is something else they can contribute to be supportive. They want to get information from the midwife to increase their participation. The expectant fathers try to find their role but they need some guidance, from the midwife about how to act and when. During the birth, and especially as the woman is bearing down, the fathers try to coach their partner. At the same time, they also express difficulties in being involved in that phase since the communication between the woman in labour and the midwife is very intense. They understand this issue, but it would help if they were given this information beforehand. The fathers know that the presence of and communication with the midwife are important when building a team - a team comprising the woman in labour, the father and the midwife. It is important to be able to ask questions, get tangible proposals, and in that sense be able to help the woman giving birth.

"We had a good relationship ... the midwife encouraged this good relationship and she gave me some tips about how to do things...act with X, calm her, where I should hold her and how I should push...pull her knees, I stood by the side and kept the head and pulled the knees, she showed me and that was very good. She instilled confidence and you felt that you did something helpful and at the same time it helped me to be in the position ...helping...you could in some way help." (5)

In addition to informing fathers how to behave during the birth, interaction with the midwife also helps them to find their role; this strengthens them in their supporting role and also confirms that they are part of a unit. At the same time, the fathers express that it is important that the midwife understands how much she can involve the father. 


\section{Meeting their child for the first time}

The fathers expressed that the first encounter with their child awoke much stronger feelings than they ever could have imagined. They describe a relief that the painful throes of childbirth are at last over. There is also a worry if everything is alright with the child; the fathers register the staff checking the baby and listening for its first scream. The fathers describe how wonderful it feels when the baby is put on the mother's breast and compare their feeling to being in love. There is a jittery feeling in the body and a strong urge to care for this new life. All the difficult things just disappear and pure happiness is left.

"I have always tried to be confident... but now I have to be even more confident. Now I have to grow like an oak. Put out even bigger and stronger arms and... embrace this and...take care of this little mite...” (4)

The birth of the first baby could be a different experience from the one the expectant father prepared for. Instead of the supposed happiness, there could be feelings of shock. There is a clash between the conception they held about childbirth and reality. The child could look different to what they expected; indeed one of the fathers describes how shocking and unexpected it was to receive a child covered with vernix. In the movies he had seen, the baby was clean when it was delivered to the parents. In his opinion, the birth of the child was dirtier and more disgusting than he thought it would be.

The fathers express that it is difficult to understand the process of childbirth and also what happens afterwards, e.g. the check-ups that are done and the Apgar test.

"...the midwife says that now I see the head I must keep on... plop... literally ...plop - the child is lying there... and I did not understand a single thing, the baby was there screaming...they took care of the afterbirth and I thought it was really strange...but the child is lying there...afterwards I understood that if the baby is lying there and screaming everything is great" (6)

The fathers describe their first encounter with their first child as simply the greatest event in their lives. They are proud that they came through the birth and they are grateful for this new life. At the moment their first child is born, there are no thoughts - just feelings and an insight that life has now changed and something new is to come.

"This is a contrast that is so genuinely positive...that is so genuine...then it feels like something really really fantastic had come into your life. Like a contrast to...to be 
honest...those things which aroused many negative feelings and so...previously in life. You are so happy and grateful. Simple as that.” (3)

\section{Discussion}

The goal in the present study was to identify and describe first-time fathers' experiences of normal childbirth. The fact that expectant fathers describe childbirth as a transformative experience in life where they are hit by strong emotions and need confirmation in their supporting role has been found in several studies (Bäckström \& Hertfelt Wahn, 2011; Johansson et al., 2015; Johansson et al., 2012; Lindberg \& Engström, 2013; Premberg et al., 2011).

When preparing for childbirth, expectant fathers describe the encounter with delivery care as a totally new experience. This is a big event and there is a need to be able to prepare themselves. Our findings are confirmed in a study by Hallgren et al. (1999), which show that Swedish men's presence at childbirth is more demanding than they expected and they feel unprepared for the process, the pain of their partner, and their own reactions. According to Bergström et al. (2013), fathers-to-be who are unprepared are at risk of negative childbirth experiences. Through preparation and exercising a coaching role, expectant fathers can have a better childbirth experience (Bergström et al., 2013; Dellmann, 2004). The midwife at the maternity welfare unit plays an important role here, regardless if the expectant father takes part in the parent education course. By encouraging the father to participate in the meetings with the midwife, the midwife has the possibility to talk to the father in a way he will understand and thus build a base for understanding the childbirth process. Nevertheless, there are difficulties in giving sufficient facts to first-time fathers since it can be hard for a person who has not yet experienced childbirth to fully appreciate the reality of the process (Hildingsson et al., 2011).

The expectant fathers are in a vulnerable situation and experience inner stress. They try to hold themselves together and act calmly, taking on the role of a supportive partner. Li Poh et al. (2014) describe that expectant fathers modify their behaviour in order to manage the emotions of fear and to not show these feelings to their partner. According to Premberg et al. (2011), the midwife should avoid stereotypical expectations of male behaviour since there is a 
risk that the fathers hide their negative emotions in order to put up a strong front, which can be hard to maintain during childbirth.

In the present study, the expectant fathers sometimes experience fear during childbirth, caused by what is happening naturally as well as the actions taken by the medical team. During childbirth a responsible midwife needs to appreciate the situation and give adequate information to the father. The midwife needs to give the right amount of information at the right time in order to reduce fear and anxiety. Hildingsson et al. (2011) state that decisive factors for expectant fathers to have positive experiences of childbirth are the presence of the midwife in the delivery room, information for the father, and support from the midwife. Communication with the midwife is an important aspect when reducing the fear and vulnerability of the father and involving him in the whole process (Lindberg \& Engström, 2013).

The fathers express some frustration at not knowing their role and the importance of their role during childbirth. These findings are in agreement with other studies showing that expectant fathers view themselves as an obvious part of the birthing couple. The healthcare system sees the father as an accompanying partner, which makes it hard to be completely involved (Chandler \& Field, 1997; Steen et al., 2012). It is important for the expectant father to be recognized as a part of a birthing unit, i.e. treated as an important part in the process, which has an effect on his experience of childbirth. The expectant fathers feel that it is important to be recognized as a part of a unit, a birthing couple. This recognition will bring forth respect to him as an expectant father and make him a part of the unit, which will influence his experience of the birth. Being involved will also help him to be more comfortable in this new and unfamiliar situation - not just an onlooker beside the woman (Bedford \& Johnson, 1988; Longworth \& Kingdon, 2011; Premberg et al., 2011).

In a study of the experiences of women giving birth, it was shown that the expectant father's presence during childbirth was very important and his role was significant in many ways. More knowledge is needed about how the expectant fathers can be prepared for childbirth and how they think about teamwork (Kainz et al., 2010). The midwife is the person who, through support, can make a difference regarding the expectant fathers' experiences of childbirth and their own role (Johansson et al., 2015; Longworth \& Kingdon, 2011). The expectant fathers in our study wondered if they did enough during the birth. One reflection about this could be 
whether the midwife assumes that the father knows what to do and when. Everything during childbirth is obvious and familiar to the midwife, so there is a need to both empower and recognize the expectant father. If the midwife's attitude changes from focusing on the woman giving birth to focusing and supporting the birthing couple, then the unit the expectant fathers are striving for becomes a reality.

Several studies have presented the overwhelming emotions and the awareness about how life changes and parenthood begins when a child is born (Deave \& Johnson, 2008; Ives, 2014; Longworth \& Kingdon, 2011). Schumacher and Meleis (1994) described how the attitude of the people involved influences the transition to parenthood. Ives (2014) points out that expectant fathers may feel their importance is reduced because the child and the expectant mother are supposed to have a close bond. When an expectant father steps forward and feels the situation is odd and wrong, he then takes a step back. This could be a reason why they minimize their own role (Ives, 2014). By using his or her knowledge, a midwife can emphasise the importance of the expectant father and support his role during childbirth, enhancing the transition to parenthood (Hildingsson et al., 2010).

The fathers are satisfied with childbirth despite feeling like an outsider. This could be due to the fact they feel grateful and relieved that the childbirth went well - for the baby, their partner and themselves. It could also be that they did not expect more: they expected themselves to be outsiders since they are not as important as the woman giving birth. Our findings give healthcare professionals working in maternity care and birthing units something to reflect upon: how these apprehensions are created and by whom.

\section{Limitation and strengths}

The limitation of this study is that it is a small sample of first-time fathers; there were difficulties recruiting only first-time fathers. Kvale and Brinkman (2014) recommend a sample size of $15 \pm 10$, depending on the aim of the study and if rich information is given in the interviews. Another limitation could be that all the first-time fathers went through the childbirth process at the same hospital. A strength is the variation of age and characteristics among the interviewees (Patton, 2015). 


\section{Conclusion and implications for practice/research}

As these findings show, the expectant fathers strive to be a support to the woman giving birth by being present and accessible, regardless of her wishes. The fathers describe difficulties in finding their role and they want to be seen as an important part of a couple, a birthing couple, even if the woman is the main focus. The fathers go through a range of emotions during the birth and the midwife is seen as the person who, by interacting with the fathers, can help them manage their emotions and also find their role. Information and support directed to the fathers from the midwife is viewed as reassuring and strengthening.

In today's society there is the expectation that fathers are equal parents in all areas, and this highlights the issue that they are made visible as important persons at the start of children's lives. This should begin at the point of childbirth. One suggestion is that the midwife invite the expectant father to a private conversation to discuss his wishes, which should contribute to making his needs visible and also emphasise his importance in the process. During the birth, the midwife can strengthen the expectant father's involvement, which may lead to a more positive experience of childbirth.

There is also a need for further research about midwives’ experiences of working with expectant fathers and how the genesis of attitudes fortifies fathers' views about themselves and the different roles that arise in parenthood.

\section{Conflict of interest}

This research is not subject to any financial or personal interests which could have inappropriately influenced the results of the study. 


\section{References}

Amato, P. R. (1994). Father-child relations, mother-child relations, and offspring psychological well-being in early adulthood. Journal of Marriage and The Family 56 (11), 1031-1042.

Bäckström, C. \& Hertfelt Wahn, E. (2011). Support during labour: first-time fathers' descriptions of requested and received support during the birth of their child. Midwifery 27, 67-73.

Bedford, V. A. \& Johnson, N. (1988). The role of the father. Midwifery 4, 190-195.

Bergström, M., Rudman, A., Waldenström, U. \& Kieler, H. (2013). Fear of childbirth in expectant fathers, subsequent childbirth experience and impact of antenatal education: subanalysis of results from a randomized controlled trial. Acta Obstetricia et Gynecologica Scandinavica 92 (8), 967-973.

Bogren Jungmarker, E., Lindgren, H. \& Hildingsson, I. (2010). Playing second fiddle is okay - Swedish fathers' experiences of prenatal care. Journal of Midwifery and Women's Health 55, 421-429.

Braun, V. \& Clarke, V. (2006). Using thematic analysis in psychology. Qualitative Research in Psychology 3, 77-101.

Chandler, S. \& Field, P. A. (1997). Becoming a father. First-time fathers' experience of labor and delivery. Journal of Nurse-Midwifery 42 (1), 17-24.

Deave, T. \& Johnson, D. (2008). The transition to parenthood: What does it mean for fathers? Journal of Advanced Nursing 63 (6), 626-633.

Deave, T., Johnson, D. \& Ingram, J. (2008). Transition to parenthood: The needs of parents in pregnancy and early parenthood. BMC Pregnancy and Childbirth 8 (30), doi:10.1186/14712393-8-30

Dellmann, T. (2004). "The best moment of my life": A literature review of fathers' experience of childbirth. Australian Midwifery Journal of Australian College of Midwives 17 (3), 20-26.

Flick,U., von Kardoff E. \& Steinke I. (2004). A companion to Qualitative Research. SAGE Publications: London.

Hagström, C. (1999). Man blir pappa. Föräldraskap och maskulinitet i förändring. (You become a father. Parenthood and masculinity in changes) Nordic Academic Press: Lund.

Hallgren, A., Kihlgren, M., Forslin, L. \& Norberg, A. (1999). Swedish fathers' involvement in and experiences of childbirth preparation and childbirth. Midwifery 15, 6-15.

Hildingsson, I., Cederlöf, L. \& Widén, S. (2011). Fathers' birth experience in relation to midwifery care. Women and birth 24, 129-136. 
Hildingsson, I., Thomas, J., Karlström, A., Engström Olofsson, R. \& Nystedt, A. (2010). Childbirth thoughts in mid-pregnancy: Prevalence and associated factors in prospective parents. Sexual and Reproductive Healthcare 1, 45-53.

Ives, J. (2014). Men, maternity and moral residue: Negotiating the moral demands of the transition to first-time fatherhood. Sociology of Health \& Illness 36 (7), 1003-1019.

Johansson, M., Fenwick, J. \& Premberg, Å. (2015). A meta-synthesis of fathers' experiences of their partner's labour and the birth of their baby. Midwifery 1, 9-18.

Johansson, M., Rubertsson, C., Rådestad, I. \& Hildingsson, I. (2012). Childbirth - an emotionally demanding experience for fathers. Sexual and Reproductive Healthcare 3, 11-20.

Kainz, G., Eliasson, M. \& von Post, I. (2010). The child's father, an important person for the mother's well-being during the childbirth: a hermeneutic study. Health Care for Women International 31, 621-635.

Kvale, S. \& Brinkmann, S. (2014). Den kvalitativa forskningsintervjun.( The qualitative research interview) Studentlitteratur AB: Lund.

Li Poh, H., Siew Lin Koh, S., Seow, H. \& He, H-G. (2014). First-time fathers' experiences and needs during pregnancy and childbirth: A descriptive qualitative study. Midwifery 30, 779-787.

Lindberg, I. \& Engström, Å. (2013). A qualitative study of new fathers' experiences of care in relation to complicated childbirth. Sexual and Reproductive Healthcare 4, 147-152.

Longworth, M. K., Furber C., \& Kirk, S. (2015). A narrative review of fathers' involvement during labour and birth and their influence on decision making. In press http:// dx doi.org/ 10.1016/j.midw.2015.06.004

Longworth, H. L. \& Kingdon, C. K. (2011). Fathers in the birth room: What are they expecting and experiencing? A phenomenological study. Midwifery 27, 588-594.

Lundgren, I. \& Berg, M. (2007). Central concepts in the midwife-woman relationship. Scandinavian Journal of Caring Sciences 21, 220-228.

Patton, M. Q. (2015). Qualitative research \& evaluation methods. 3rd ed. SAGE publications: London.

Peterson, G. H., Mehl, L. E. \& Leiderman, H. (1979). The role of some birth-related variables in father attachment. American Journal of Orthopsychiatry 49 (2), 330-338.

Premberg, Å., Carlsson, G., Hellström, A-L. \& Berg, M. (2011). First-time fathers experiences of childbirth - A phenomenological study. Midwifery 27 (6), 848-853.

Schumacher, K. L. \& Meleis, A. I. (1994). Transitions: A central concept in nursing. The Journal of Nursing Scholarship 26 (2), 119-127. 
Steen, M., Downe, S., Bamford, N. \& Edozien, L. (2012). Not-patient and not-visitor: A metasynthesis of fathers' encounters with pregnancy, birth and maternity care. Midwifery 28, 422-431.

SFS. Svensk författningssamling, SFS 2003:460. Lag om etikprövning av forskning som avser människor. (Law about ethical approval regarding research on humans) Accessed 0403-2015 http://www.riksdagen.se/sv/Dokument-Lagar/Lagar/Svenskforfattningssamling/Lag2003460-om-etikprovning_sfs-2003-460/

SFS.Svensk författningssamling, SFS 2008:192. Lag om ändring i lagen (2003:460) om etikprövning av forskning som avser människor.( changes in the law about ethical approval...) Accessed 09-03-2015 http://www.notisum.se/rnp/sls/sfs/20080192.pdf

Trautmann-Villalba, P., Gschwendt, M., Schmidt, M. H. \& Laucht, M. (2006). Father-infant interaction patterns as precursors of children's later externalizing behavior problems. European Archives of Psychiatry and Clinical Neuroscience 256, 344-349.

Vehviläinen-Julkunen, K. \& Liukkonen, A. (1998). Fathers' experiences of childbirth. Midwifery 14, 10-17.

WMA. (2013). Declaration of Helsinki - Ethical Principles for Medical Research Involving Human Subjects. Accessed 08-02-2015 http://www.wma.net/en/30publications/10policies/b3/index.html 


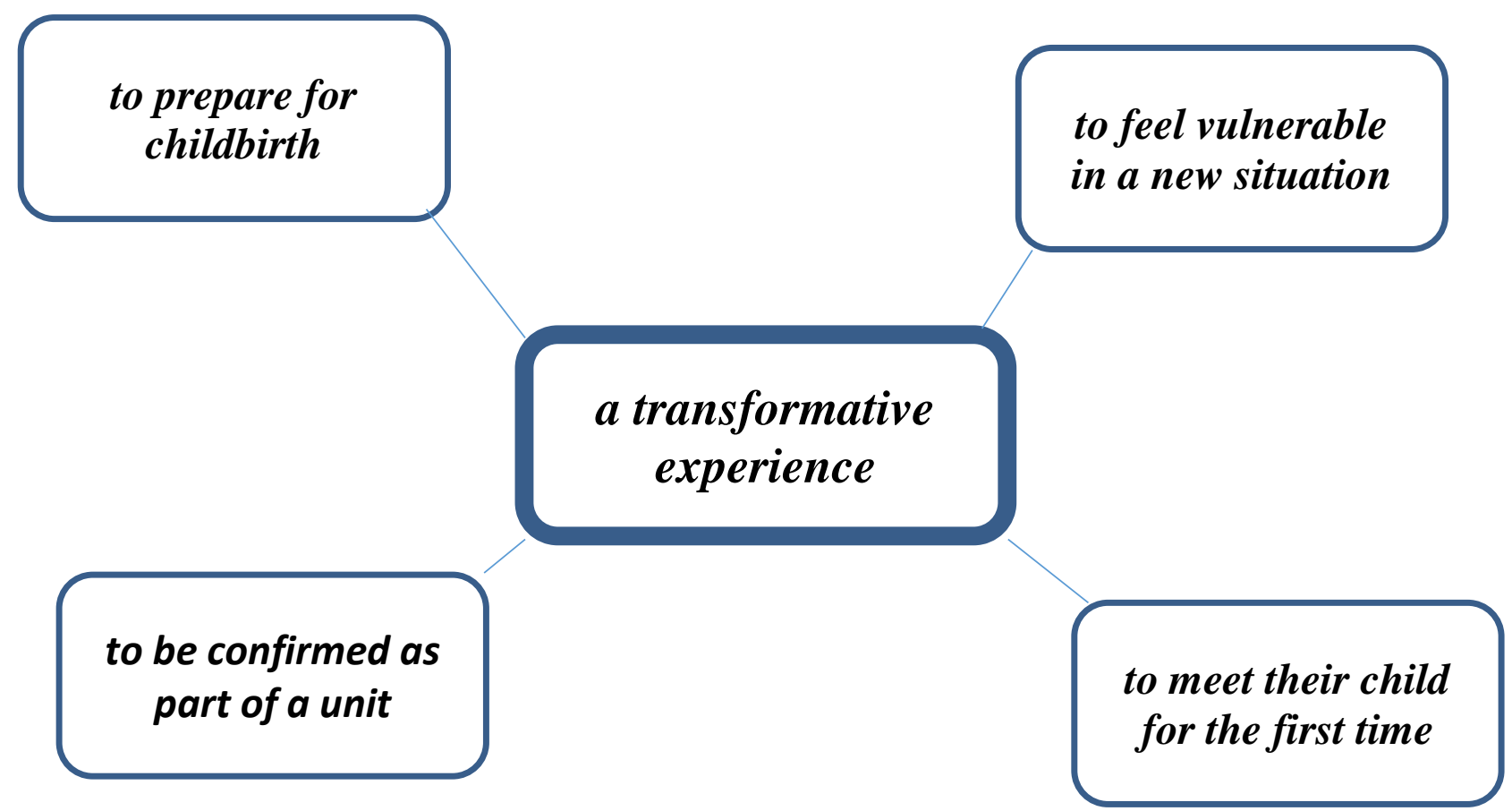

Figure 1. Main theme and subthemes that identify and describe first time fathers' experiences of a normal childbirth 